\title{
Thinking about Thinking: Can the Face Be a Window to the Mind?
}

\author{
Allen Tager \\ Independent Researcher, USA \\ Email: allentager999@gmail.com
}

Received 13 March 2016; accepted 4 July 2016; published 8 July 2016

Copyright (C 2016 by author and Scientific Research Publishing Inc.

This work is licensed under the Creative Commons Attribution International License (CC BY). http://creativecommons.org/licenses/by/4.0/

c) (i) Open Access

\begin{abstract}
Mankind is on the verge of an evolutionary breakthrough that has the potential to transform the human way of life. In this manuscript I propose a new approach to education, which focuses on developing the "intuitive mind". This proposed "Triple I" formula of education (instinct + intellect + intuition) involves a much more thorough integration of personality aspects and internal synthesis, which fosters independent creative thinking and promotes the group's interests. Here I detail the scientific rational for this proposal, while also exploring a potential scientific tool to guide such educational training. Based on current scientific research, I hypothesize that facial luminosity patterns can be used as a sort of "fingerprint" to identify intuition's dominated thinking patterns in individuals. This technology can be developed to provide a window into the mind of a person, and in this way can guide efforts to develop an evolutionarily more advanced state of thinking led by the intuitive mind.
\end{abstract}

\section{Keywords}

Intuition Development, Theory of Mind, Mind Evolution, Creative Education, Evolution of Cognition, Evolution of Perception, Ultraweak Photon Emission, The Triple "I" Approach in Education

\section{Introduction}

Nowadays, the scale of each individual is determined by the scope of his or her thinking. To explore these notions in greater depth, this paper focuses on the scope and nature of thinking and on articulating what "the scope of thinking” might mean. It also reveals the plethora of perspectives on the nature of thinking, raises issues concerned with pedagogy, and suggests the need for the field to build consensus on the scope, nature, and structure of modern thinking. 
Researchers at the Massachusetts Institute of Technology have developed a system they call the Data Science Machine, which recently beat out over 600 human teams in finding predictive patterns buried in unfamiliar data sets (Kanter \& Veeramachaneni, 2015). Instead of taking months to come up with prediction algorithms like the human teams, the machine took less than one day. The defeat of the intellectuals in the competition with the computer is primarily a reflection of the fact that the intellectual ability to think rationally proved to be no match for artificial intelligence. A purely logical, intellectual type of mind, like those of the human contestants, has its limits. "Our thought, in its purely logical form, is incapable of presenting the true nature of life, the full meaning of the evolutionary movement” (Bergson, 1907). This fact raises the question of what the role of intellectual abilities at this stage of human evolution is, and the necessity for its transformation into a more advanced system of thought. In this sense, the current situation is absolutely unique.

\section{The Triple "I" Approach}

During human evolution, the intellectual mind evolved as a higher order function after the instinctive mind and the uniqueness of the current state lies on the fact that over the past centuries mankind has passed one of the necessary stages - the massive development of intellectual abilities and the formation of the intellectual mind. Intellect is responsible for the systematization and preservation of knowledge, thereby allowing information accumulated in the past centuries to reach the students of today. It is closely related to memory and repetition of the past; it is based on the accomplishments of the past. Intellect focuses on established knowledge, but multi-faceted reality is too complex for just pure intellectual approach. As the predictable and logical result, current educational model cannot keep up with the highly dynamic nature of today's technologically advanced world, where knowledge and information are changing day to day. A bright example of this is the business world. Modern business relies on fast development and permanent expansion, where the concrete formation of the future is the way to guarantee success. Focusing merely on the knowledge of the past is generally not enough to solve problems, as the past is never current enough. As a result, business and education are heading in two different directions.

The intellectual mind has been productive in the past, and will benefit mankind for quite a long time; nevertheless, in the present time, mankind is on the threshold of a new and much more significant evolutionary step and the universal desire to improve the quality of education is the strongest evidence of this. What will be the next step in human evolution? Bergson again: "Theory of knowledge must take account of these two faculties, intellect and intuition” (Bergson, 1907). From this point of view, what is happening today is the acceleration of mental development through what is so-called "mental polarization” (Bailey, 1954), which has become the central focus of human evolution, and led man to the stage where he prefers to think for himself. As is obvious, mankind is currently on the cusp of another great leap of mind evolution.

There are three ways of seeking knowledge. One method, familiar to everyone, is understanding the wellknown, which is crucial for survival and which every child should learn before schooling. The second, intellectual method is more complex: it moves from the realm of the known to the known. Intellectual thinking consists of deduction or inference, which is the rational abilities of the mind; however, rational logical arguments are only one part of deeper mental processes. "The intellect selects in a given situation whatever resembles something it already knows, or is familiar with; it seeks this out to apply its principle that 'like produces like” (Bergson, 1907). And then there is the third, least common way of knowledge: movement from the known to the unknown. "Whenever one proceeds from the known into the unknown, one may hope to understand but may have to learn at the same time a new meaning of the word 'understanding'” (Heisenberg, 1958).

Historically, philosophers have tried to make sense of thinking (i.e. cognition) by classifying and describing "types of minds". Three types of those mind concepts are: instinctive, intellectual, and intuitive (Plato, 380 BCE; Bacon, 1620; Descartes, 1641; Hegel, 1807; Kant, 1787; Bergson, 1907; Weyl, 1917; Mursell, 1919; Heisenberg, 1958). The most basic ‘instinctive' mind is crucial for survival; it consists of so-called 'common sense' and the primitive ability to trick others. The second, higher level is the intellectual mind, emerging in the process of education; it is the rational, analytical aspect of thinking. The third, and considered the most sublime form, is the intuitive mind. "It is by logic we prove, but by intuition that we discover" (Poincare, 1908). The notable characteristic of the intuitive mind is an independent way of thinking. This type of mind is mostly seen in leaders in philosophy and psychology, science and culture, business and finances, progress-oriented politicians and benefactors to society. 
Intuition is not analytical and not to be confused with instinct - it is above both the animal part and rational thought. The latter can form a question; intuition finds the answers. "All human knowledge begins with intuition, proceeds from thence to concept, and ends with ideas” (Kant, 1781). Instinct relates man to the animal world, intellect unites him with other humans, and intuition reveals the hidden laws of life (Bailey, 1954). Intuition is free from emotions and selfless; it strives towards the greater good of humanity.

Since the Stone Age, mankind has developed in three stages, from the simplest instinctive mind, to the higher intellectual and intuitive minds. All three begin with the letter "I", it is logical to group them together in a simple and easy-to-remember formula-The Triple "I". Traditional education develops only the first two aspects of the human being-instinctive and intellectual minds. This approach can be described in a simple formula:

$$
\text { Instinct + Intellect = The Double "I" }
$$

However, the new approach in education combines all three aspects of human nature: instinct, intellect, and intuition, with a main focus on developing intuition. This formula of education involves a much more thorough integration of personality aspects and internal synthesis, which is mandatory for continued progress.

$$
\text { Instinct + Intellect + Intuition = The Triple "I" }
$$

Without the support of key linguistic formulas, it is difficult to discuss the new phenomenon for which adequate scientific, philosophical or psychological languages have not yet been created. The Triple "I" formula was created to fill this void as it adequately expresses the notion of the synthesis of all three approaches in education.

Moreover, from a psychological point of view, the triple "I" helps to reach a clear understanding that each person who follows his own artistic, scientific, philosophical, or business nature pursues the comfortable "way of least resistance” (Bailey, 1954). The main goal of the educator becomes to define and encourage these approaches. It can change the way humankind thinks; intellectual speculations will be replaced by objective personal knowledge of the reality. At the same time it cannot be neglected the development of the intellectual mind, as one of the most important roles of this type of thinking is required for translating discoveries of intuition into a format understandable to public; it should be kept the relationship of these two levels of thought.

\section{Materials and Methods}

Despite the variety of techniques for opening intuition, the essence of this process is easy to describe. Guided by intuition, a teacher needs to generate a situation where the student's memory and knowledge of experience from the past becomes completely useless. When it is impossible to lean on the past, and the ephemeral present does not help, the survival instinct pushes students to look for support from the future. This stimulates their inner mechanism of turning on intuition's switch. After having several successful experiences, every student is able to remember his/her specific internal mechanism for activating intuition. To sum up, intuition is not born on the basis of the past, but on the basis of the future.

The development of intuitive thinking is a complex process and its structure cannot be described in a limited article's format. However, the following example provides insight into the essence of the process. The first step in the process of liberating one's self from the past is the selection of topics. For example, the topic 'The birthplace of the ocean' is not only about the specific place but also the process of the birth of the first drop of water on the planet. Another challenging topic is 'The black square', which directly connects to the thin boundary condition of wakefulness and sleep. In most cases, it is associated with the dark square or rectangle of a bedroom window, where every night, like on a movie screen, a mix of daily events and intuitive insights come to life. Refocusing attention on timeless intuitive insights and fixing them on paper gives each participant the opportunity to see their foundation and architecture, and finally makes them meaningful. This gives them the chance to understand the importance of objective subtle states of consciousness and thinking in their lives.

The mechanism of opening intuition is held in five phases:

1. Concentration,

2. Focus on a particular question,

3. Contemplation,

4. Enlightenment,

5. Inspiration.

This is a technique that each student should study and it is important to emphasize that this is a purely scientific process of understanding the reasons causing certain consequences. It has nothing to do with emotional or religious experiences. 
From the point of understanding the universal phenomena, each student has to link it to a concrete life situation. In such a moment they should use their developed intellectual mind, which helps to translate sophisticated ideas into scientific or verbal forms understandable for the public.

Not every person is ready to move into the unknown future alone. In such a moment, the teacher's intuition plays a crucial role; the teacher should move into the future of each student together with them and not interfere with the student's efforts and movement. The group discussion of the finished drawings is gives a chance to look at each participant's breakthrough into the future through the eyes of other students, who are able to add more profound interpretation to each of the discussed drawings. The role of the teacher is to focus on the pictures that appear as a result of opened intuition, and focus the group's attention to the hidden mechanisms of the work of intuitive, intellectual, and instinctive minds. Here is just an approximate description of what is happening; talking about intuition is not easy, as in human language there are no equivalent terms describing the structure of intuition and its capabilities. Where there is no equivalence in the language, there is no equivalent in the human mind; to understand intuition, man needs intuition.

The development of intuition does not depend on the subject being studied. Two simple tools: paper and a few colored pencils, are enough to start the most astonishing process of human life, opening the channel of intuition, which can turn an ordinary person into a creator. The ability to draw is not required, as each person's unique handwriting already contains all individual data about his/her character and temperament, and drawing is only an extension of the innate ability to write combinations of a unique design of letters. One of the most important indicators of intuition is not the creation of works expressed with harmonious forms, but the extension of a unique color perception. Colors are often mistaken as just a property of light, when it really is the mind that enables humans to fully process and perceive colors (Williams et al., 2005). Thought determines everything. A new thought must be born before it can play a role in creating a meaningful vision of a new reality in the familiar world and the quality of thought determines color receptivity. The quality of thinking is a major factor in improving the chemical, genetic, and functional levels, which determine the quality of color discrimination. "Who knows the secret of color, he knows the secret of life... When students learn to distinguish colors beyond the familiar spectrum it strongly encourage intuition, and quickly develop the intuitive mind. Gradually students learn to distinguish not only infinite shades of color, but also the unique shades of each human being” (Bailey, 1934).

Besides, there is no time limit for intuition to return to any historical era in the past or move into the future; time disappears when intuition is on. Humans have developed sophisticated concepts like time and space to explain a wide range of everyday phenomena, but how such concepts are represented by the brain and mind is still an enigma. When people try to describe any phenomena in terms of time, they are aware that no representatives of the animal world are able to do so; it is only the prerogative of man. But, one of the known ironies of life is that even though everyone knows what time is, one doesn't have any idea of what it actually is.

The theory of relativity states that there is no unique absolute time, and that each individual has his or her own measure of time, depending on their location and movement (Einstein, 1905). Therefore, space and time have become dynamic entities. Not only do they affect everything that happens in the universe, but they also depend on it. But what is the essence of this 'own measure', and what is the reason for the 'measure of time'? The theory does not give an answer to these questions. Even Einstein stated, "People like us, who believe in physics, know that the distinction between past, present and future is only a stubbornly persistent illusion" (Janssen, 2002). The leading physicist of present time, Edward Witten, said, "Space and time may be doomed” (Cole, 1999). Another American physicist Nathan Seiberg confirmed Einstein’s statement, "I am almost certain that space and time are illusions. These are primitive notions that will be replaced by something more sophisticated” (Cole, 1999). And David Gross summed up the views of many physicists when he stated in his public speech of the coming revolutions in theoretical physics saying, "We have no idea what it might mean to formulate physics without time” (Gross, 2007). "The real change that’s around the corner [is] in the way we think about space and time” (Gross, 1999).

Before making any inferences it should be known why and how time was born. The idea of creating a timeline reflects a purely pragmatic human attempt to create a convenient tool to support mans' mechanistic civilization. Therefore humans create a simple measure of dividing the past, present, and future. The notion of time seems like nothing more than the technique of a pragmatic assessment of realities, created by a combination of common sense and an intellectual approach to life. However, this was a necessary step in the long process of human development. Due to the fact that scientific thought is progressing incredibly fast in the 21st century, it can be assumed that the existing interpretation of time might soon become just a part of science history. 
There are many interpretations of time throughout history. Antiphon, an ancient Greek philosopher said, "Time is a thought or a measure, not a substance", and Joseph Brodsky stated that, "Time, in fact, is the thought of a thing” (Glad, 1992). For a better understanding of the nature of time, let me bring up for discussion the rather paradoxical hypothesis that time is no more than a "length of thought" (Bailey, 1934). The most powerful argument in defense and support of such a non-conventional definition of time is a simple analysis of humans daily life, as the fixation of time only happens when people are fully awake/aware, when people are not under the influence of drugs or alcohol, not in a coma, not daydreaming, they do not argue with the other, etc. There are so many situations where people do not notice the time, even while awake, that there is no need to list them all. Let's write the proposed hypothesis in the form of a simple, easy-to-remember formula:

Time = length of thought

As soon as it can be accepted the new definition of time, humans face the possibility of the existence of the higher form of thinking, for which the concept of time and space are no longer limiting factors. Intuition is not only able to go back in time, but without changing the event, it is able to change its quality, which in turn leads to a global change in the present and the future. Such new experience becomes a revelation for the majority of students; it brings up a precise idea of causation together with the full understanding who is who around them. It helps to reach the freedom of transforming the past and build new approaches to life and relationships with others.

\section{Can the Face be a Window to the Mind?}

The understanding of the intuitive mind requires focused scientific research. Determination of the centers of the brain responsible for the work of intuition and creativity can transfer the discussion from intellectual speculations and assumptions, to the field of proven facts and give powerful impetus to the development of this new Triple I approach in education. Thanks to intensive scientific efforts, the first important steps in this direction have recently been made by three research groups.

While the relationship between the work of neural circuits of the brain and intelligence seems obvious, the hypothesis of 'neural efficiency', which was long used as an assumption by most neuroscientists and psychologists, was recently confirmed experimentally (Smith et al., 2015). Studies of human intelligence provide strong evidence for the neural efficiency hypothesis, which suggests more efficient brain functioning (i.e., less or more focused activation) in more intelligent individuals. Another group of researchers demonstrated that functional connectivity profiles act as a 'fingerprint' that can accurately identify subjects from a large group (Finn et al., 2015). The results from this experiment also indicated that an individual's connectivity profile is intrinsic, and can predict levels of fluid intelligence. The variation of brain functioning in different people should be examined (Stern et al., 2015).

There is no doubt that one day the dedicated efforts of the many scientists studying the relationships between the brain, cognition, and intelligence will lead to the desired result, but humanity is at the peak of the crisis and cannot wait. But, as often happens, the conclusion has already been reached, and is only waiting to be uncovered.

One of the most significant discoveries in biophotonics, which is related to psychology, philosophy and education, has passed virtually unnoticed. It has long been known that a significant amount of light penetrates the skull and reaches the brain in mammals (Brunt et al., 1964; Campbell et al., 2001; Persinger et al., 2013). Recent studies show that the human body emits its own light, in a phenomenon known as "ultraweak photon emission" (Kobayashi et al., 2009). The strength of this emission is a thousand times lower than what can be detected by the naked eye, but can be measured via scientific cameras. The experiment helped provide the scientists with an opportunity to see the luminescence of cells in vivo in absolute darkness. Perhaps most extraordinary of all, is the possibility that all living organisms emit a constant current of light particles (biophotons). This phenomenon is most pronounced in the human world. The human body literally glimmers; it emits and is actually made from light, and the most intriguing part is that the strongest vibrant cell luminosity was found in the skull/heads of all volunteers studied. Another group of scientist confirmed Kobayashi's discovery and proved that photons are emitted during brain activity and bright light transmits through the brain (Persinger et al., 2013).

The brain is the organ with the highest energy consumption in the human body, accounting for up to $20 \%$ of total consumption, and "Energy follows thought” (Dotta et al., 2012). Therefore if each thought pattern generates energy, and this energy is translated to a luminescence of the face that can be measured by cameras, then it might be possible to use the pattern of luminosity as a measure of the 'mind' state. Specifically, it might be 
possible to differentiate between which of the three types of minds: instinctive, intellectual and intuitive, is dominant. Thus this 'picture' can be used as a reflection of the brain, and may give a sort of objective 'fingerprint', showing the mental status of a person on the evolutionary ladder. One of the most notable discoveries confirming the direct link between the cells glow intensity and quality of the emerging life was recently made by a group of American researchers led by Teresa Woodruff et al. (2016), focusing on female reproductive health and infertility. Researchers from Northwestern University in Chicago noted that some female eggs glow brighter than others, thus showing that they have a better chance of getting a healthy child. In the future this discovery should help physicians involved in the problems of artificial insemination to choose the highest quality reproductive material.

In a broader sense, light is the key factor and, based on a generally accepted paradigm, light is the language of the Universe (Bailey, 1954). In terms of evolution, the intensity of emitted light should be assessed as one of the most striking features of an organism and the defining point of the organism on the evolutionary scale. Just by measuring the intensity of the luminosity of cells of different creatures should give researchers an idea of their level of evolution at any given time. However, in human evolution, the intensity of luminosity of cells reflects the progress in reaching such mental states as intellect, open-mindedness, awareness, or wisdom. Therefore, in many natural forms of life, the level of luminosity of minerals, vegetation and animals, as well as in humans is the first and possibly the most important sign of a more advanced level of consciousness.

\section{Discussion}

The strength of a person consists of two major components-the ability to think independently and a high level of responsibility. The new educational approach provides solid foundation for the inner psychological balance of each student, which is based on deep knowledge of one's self, as well as their particular talent, role in society, and clear goal in life. Another important aspect of the psychological balance is that the traditional destructive competition should be replaced by cooperation, the basis for which is not a painful comparison with the others, but only the personal development from good to better. In other words, it should be developed active 'mental polarization', which refers to the gradual development of the mental capacity of humanity and the transition from simple forms to more complex levels of thinking. It implies not only the full development of the intuitive mind, but the liberation from the control of distractive instincts and accompanying emotional reactions as well as intellectual speculation and, thus, this guaranties psychological stability and balance. New principles of intuitive psychology should be formulated in contrast to the traditional emotional and intellectual psychology. These will explain the psychological mechanism of intuitive thinking and its impact on all life processes. The intuitive psychology will also be able to realize that all the laws of physics are the laws of the psyche. It would be understood that all mental processes are physical in nature and vice versa (Bailey, 1954).

Furthermore, the significance of involvements of the philosophy should be outlined. Philosophers should pay attention to the appearance and formation of the new and sufficiently large leading group in the society. Historically, only some exceptional and ambitious leaders had the power to be the society rulers and shape the history of mankind. This time the paradigm should change. Such single leaders must be replaced by a large group of open minded people which has no ambitions or personal selfish goals, but only a high level of mental power and constructive vision of reshaping the civilization. The members of the group will soon become CEOs, top managers and project leaders in all fields of human activities as well as initiate all necessary local and global economic, social and political reforms. They will be able to solve most of the problems in health, education, science, and social life. By replacing mediocrity at all levels of government structure they will be able to decrease the level of crime, stop corruption and prevent local and international military conflicts. In short, such a powerful group will stimulate and put into practice the positive reforms which affect all forms of life. It is imperative to add a new chapter on philosophical concepts reflecting such powerful changes in mankind's evolution.

"Nothing in biology makes sense except in the light of evolution", said American biologist Theodosius Dobzhansky (1973). Dobzhansky's words can be applied to all parts of life and, no doubt, to the nature of education, where all phenomena should be discussed in terms of evolution. Since intuition reveals the hidden connections combining all the elements of life in an interconnected system, it is necessary to emphasize that intuition opens relationships between matter and consciousness, the evolution of matter and form, the evolution of man, and evolution of consciousness. It teaches students to think in categories of evolution; when students understand that evolution is a creative process and man is a natural part of it, instead of acting from emotional state, 
they begin to live and act as mental leaders. They understand that freedom is not a condition of existence but is a state of mind (Bailey, 1954).

This also helps students to become more sensitive to the ideas proposed by others and realize that the basic instinct of every man is an expression of his uniqueness. Yet the presence of personality means inevitably encountering situations in which one disagrees with someone else and, as a consequence, in many situations reaching a full agreement is not possible. Students understand and accept the fact, that differences will always exist between people and nations because they are just a sign of individuality, but decision-making for conflicts from a position of strength is a sign of immaturity; two people or nations can somewhat disagree with each other, but the presence of personal opinion should not be a problem (Bailey, 1954).

This new approach can gradually change the education system. It provides the opportunity to determine the level of thinking of each student's mental potential, and offers those who are ready to develop intuitive minds an accelerated training program; instead of a 12 year program, such students would pass the school curriculum in 5 - 6 years, and their study time at university can also be halved. It can save society significant amounts of time, effort and money that can be spent on the preparation of the new generation of teachers with advanced intuitive thinking, which on the broader scale, as a chain reaction effect, will help to re-focus whole educational system to the development of higher mental qualities.

To sum up, as soon as scientist can identify the facial luminosity patterns of creative people actively using their intuition, it can be used as a measure of success for the new philosophical and educational paradigms. This new knowledge will give impetus to the much needed reform of education, and will aid the gradual transition of public and private schools and universities from the traditional approach, which is training pure intellectual ability, to the development of the higher intuitive mind. For new generations, such an approach to education will help to reach true freedom of thought, become true independent thinkers and absolute leaders in their professional activities when millions of such individuals begin to act it will quickly and effectively revolutionize all spheres of life. The progress of science and technology will become incredibly fast and civilization will take new and more humanistic shapes.

\section{Conclusions}

The ultraweak photon emission can be an invaluable tool for studying and determining the evolutionary state of human cognition. This technology may provide a window into the mind of a person, and in this way track their progress in developing a higher state of thinking.

In this light, it can be revised man's conception of human history and his relation to it, and clarify the goal of evolution. "The ultimate goal is the achievement of maximum awareness, and the essence of the history of mankind is not about the dates, events and facts, but the history of the growth of human abilities of perception" (Bailey, 1954).

The steps humanity needs to take are significant and essential, and the problems and challenges of the human world can be solved in a short amount of time if society would understand that this innovative approach is the key. Past achievement predicts future capabilities. The successful development of the intellectual mind over the past centuries builds a strong platform for the next step in evolution. Now is the time to take this step, to move from intellect to intuition, and create a better world.

\section{Acknowledgements}

I am grateful to Dr. Rezan Sahinkaya for assistance with editing which improved the manuscript significantly.

\section{Competing Interest}

The authors declare that they have no competing interests.

\section{References}

Bacon, F. (1620). The New Organon. Cambridge: Cambridge University Press.

Bailey, A. (1954). Education in the New Age (Chapter I, Introductory Statement, IV). New York: Lucis Trust Publishing.

Bailey, A. (1934). A Treatise on White Magic (p. 451). New York: Lucis Trust Publishing.

Bergson, H. (1907). Creative Evolution (pp. 1-2, 178). Los Angeles: Indo European Publishing. 
Brunt, E., Shepherd, M. D., Wall, J. R., Ganong, W. F., \& Clegg, M. T. (1964). Penetration of Light into the Brain of Mammals. Annals of the New York Academy of Sciences, 117, 217-224. http://dx.doi.org/10.1111/j.1749-6632.1964.tb48177.x

Campbell, S., Murphy, P. J., \& Suhner, A. G. (2001). Extraocular Phototransduction and Circadian Timing Systems in Vertebrates. Chronobiology International: The Journal of Biological and Medical Rhythm Research, 18, 137-172. http://dx.doi.org/10.1081/CBI-100103183

Cole, K. (1999). Time, Space Obsolete in New View of Universe. LA Times Column Section, Times Science Writer. http://articles.latimes.com/1999/nov/16/news/mn-34060

Descartes, R. (1641). Meditations on First Philosophy. Cambridge: Cambridge University Press.

Dobzhansky, T. (1973). Nothing in Biology Makes Sense except in the Light of Evolution. American Biology Teacher, 35, 125-129. http://dx.doi.org/10.2307/4444260

Dotta, B., Saroka, K. S., \& Persinger, M. A. (2012). Increased Photon Emission from the Head while Imagining Light in the Dark Is Correlated with Changes in Electroencephalographic Power: Support for Bókkon's Biophoton Hypothesis. Neuroscience Letter, 513, 151-154. http://dx.doi.org/10.1016/j.neulet.2012.02.021

Einstein, A. (1905). On the Electrodynamics of Moving Bodies. Annalen der Physik, Vol., Page.

Finn, E. et al. (2015). Functional Connectome Fingerprinting: Identifying Individuals Using Patterns of Brain Connectivity. Nature Neuroscience, 18, 1664-1671. http://dx.doi.org/10.1038/nn.4135

Glad, J. (1992). Conversations in Exile: Russian Writers Abroad. Durham, NC: Duke University Press

Gross, D. (2007). The Coming Revolutions in Theoretical Physics. Berkeley, CA: The Berkeley Center for Theoretical Physics. https://www.youtube.com/watch?v=AM7SnUlw-DU

Hegel, G. (1807). Phenomenology of Mind. Mineola, NY: Dover.

Heisenberg, W. (1958). Physics and Philosophy: The Revolution in Modern Science, Role of Modern Physics in Human Thinking (p. 175). New York: Harper \& Row. http://dx.doi.org/10.1063/1.3062735

Janssen, M. (2002) The Einstein-Besso Manuscript: A Glimpse Behind the Curtain of the Wizard. In The Collected Papers of Albert Einstein (Vols. 1-10, pp. 1987-2006). Princeton, NJ: Princeton University Press.

Kant, I. (1781). Critique of Pure Reason. Cambridge: Cambridge University Press, 1999.

Kanter, M., \& Veeramachaneni, K. (2015). Deep Feature Synthesis: Towards Automating Data Science Endeavors. IEEE International Conference on Data Science and Advanced Analytics, Paris, 19-21 October 2015, 1-10. http://dx.doi.org/10.1109/dsaa.2015.7344858

Kobayashi, M., Kikuchi, D., \& Okamura, H. (2009) Imaging of Ultraweak Photon Emission from Spontaneous Human Body Displaying Diurnal Rhythm. PLOS ONE, 4, e6256. http://dx.doi.org/10.1371/journal.pone.0006256

Mursell, J. (1919). The Function of Intuition in Descartes' Philosophy of Science. The Philosophical Review, 28, 391-401.

Persinger, M., Dotta, B.T., \& Saroka, K. S. (2013). Bright Light Transmits through the Brain: Measurement of Photon Emissions and Frequency-Dependent Modulation of Spectral Electroencephalographic Power. World Journal Neuroscience, 3 , 10-16. http://dx.doi.org/10.4236/wjns.2013.31002

Poincare, H. (1908) In Science and Method (Translated by Francis Maitland, 1914). Paris: La Valeur de la Science.

Plato (380 BCE). Republic. Indianapolis: Hackett.

Smith, S. et al. (2015) A Positive-Negative Mode of Population Covariation Links Brain Connectivity, Demographics and Behavior. Nature Neuroscience, 18, 1565-1567. http://dx.doi.org/10.1038/nn.4125

Stern, E. et al., Nussbaumer, D., \& Grabner, R. H. (2015). Neural Efficiency in Working Memory Tasks: The Impact of Task Demand. Intelligence, 50, 196-208. http://dx.doi.org/10.1016/j.intell.2015.04.004

Weyl, H. (1917). The Philosophy of Mathematics. Princeton: Princeton University Press.

Williams, D. (2005). Color Perception Is Not in the Eye of the Beholder; It's in the Brain. Journal of Neuroscience, 25.

Woodruff, T. et al. (2016). The Zinc Spark Is an Inorganic Signature of Human Egg Activation. Scientific Reports, 6, Article Number: 24737. 